\title{
Research on Wardrobe Design Based on Kansei Engineering
}

\author{
FU Kaijie ${ }^{1}$, HU Shan ${ }^{2}$, JIANG Xu $^{3}$, and JIA Qi ${ }^{4}$ \\ ${ }^{1,2,4}$ Hubei University of Technology, China \\ ${ }^{3}$ Jiangnan University, China \\ 1530572556@qq.com,2595560325@qq.com,3295316575@qq.com, \\ 4726184261@qq.com
}

\begin{abstract}
Based on the fact that most of current current wardrobe modeling is mainly from the perspective of product designing, this paper aims to explore the user's emotional needs and wardrobe modeling design elements between the relevance, so as to provide better guidance for the wardrobe modeling design. Based on the kansei engineering theory, the modeling perceptual intention of representative wardrobe samples was analyzed and the semantic database was constructed. Semantic difference method would be used to conduct perceptual evaluation of representative samples and perceptual vocabulary. On the premise of ensuring the rationality of the data, SPSS software was imported to conduct the principal component analysis and factor coefficient quantitative analysis of the perceptual evaluation data, and the main perceptual intention words and design styles affecting the wardrobe design would be obtained. Finally, a correlation model between major parts of the wardrobe and perceptual image words would be established through questionnaire survey. And the existing wardrobe styles and styles would both be improved. SUS scale would be compared with the existing wardrobe styles to verify the feasibility of the design method, and finally a theoretical reference was provided for the research on wardrobe modeling.
\end{abstract}

Keyword : Industrial design, Furniture design, Kansei engineering, Principal component analysis

\section{Introduction}

Furniture, as an important basis for the establishment of family living space, occupies an important proportion in the decoration expenditure of most families in recent years. Meanwhile, the sales volume of furniture market has been on the rise [1].Wardrobe as an important part of furniture, providing the function of clothing storage for family members, which needs to consider the structure of the wardrobe and functional design carefully, should also fully consider the perceptual needs of consumers [2], in order to ensure that the product stands out in the mass market. In the process of using the product, the color, function and structure will directly affect the user's perception of the product [3]. Therefore, these design elements should be reasonably and effectively combined in the design process to achieve the effectiveness and purpose of the design.

\section{Article history:}

Received (August 9, 2020), Review Result (September 11, 2020), Accepted (October 12, 2020) 
The theory of Kansei Engineering, (KE) originated from Japan, which was first proposed by Kenichi Yamamoto, chairman of Mazda automobile group, and later laid the theoretical foundation by Japanese scholar Miasaki Nagaishi [4]. Kansei engineering has been widely applied in various design product fields in recent years, and it is a kind of design element that transforms consumers' fuzzy perceptual words about the subjective intention of products into quantifiable design elements [5].Perceptual image is a subjective feeling of people towards objects, which can lead to consumers have a better understanding of the product modeling, so as to narrow the gap in product understanding between product designers and consumers [6][7].At present, many foreign scholars have conducted in-depth exploration and research on product design based on kansei engineering [8][9][10]. Tama et al. [11] improved the design of ceramic souvenirs by combining kansei engineering with kano model to better satisfy the needs of consumers. There are also a large number of domestic scholars who combined kansei engineering with other research methods. Su jianning et al. [12][13] used semantic difference method to construct the product modeling design system, and optimized the product modeling design through perceptual imagery, vector-supporting machine and particle swarm optimization algorithm. Liu et al. [14] quantified the aesthetic evaluation by combining kansei engineering with fuzzy theory, and redesigned a headwear which is more approached to people's understanding of mazu culture. Wang nianwen et al. [15] established the matching model of user demand and user sensibility by using the method of combining perceptual demand and perceptual words, and designed a family service robot model which could better satisfy needs of the elders. However, due to the complexity of consumers' perceptual demand for products, it is necessary to analyze the combination of product internal structure and perceptual vocabulary in order to avoid one-sided results caused by irrelevant or weak correlation between products and vocabulary. The research is based on the kansei engineering theory. Firstly, the perceptual demand and perceptual measurement values of the wardrobe are obtained. The principal component and factor analysis of the perceptual demand are carried out by using SPSS25.0 software, and the main factors affecting the modeling design are obtained. Then the comprehensive factor score is calculated and the priority order of the reference sample would be defined. The main components of wardrobe modeling are decomposed by the method of modeling chart, and the most preferred modeling image of the main components would be selected. According to the wardrobe each part of the design elements and the modeling image of the mapping relationship between the modeling design.

\section{Establishment of flow and perceptual semantic space}

Product image innovation design is mainly based on the original product modeling, combined with the needs and expectations of consumers for the product redesign, in order to meet consumers' expectations for the product as the purpose. The following is the flow chart of product modeling innovation design, which is improved according to literature [15] (showed in [Figure 1]). 


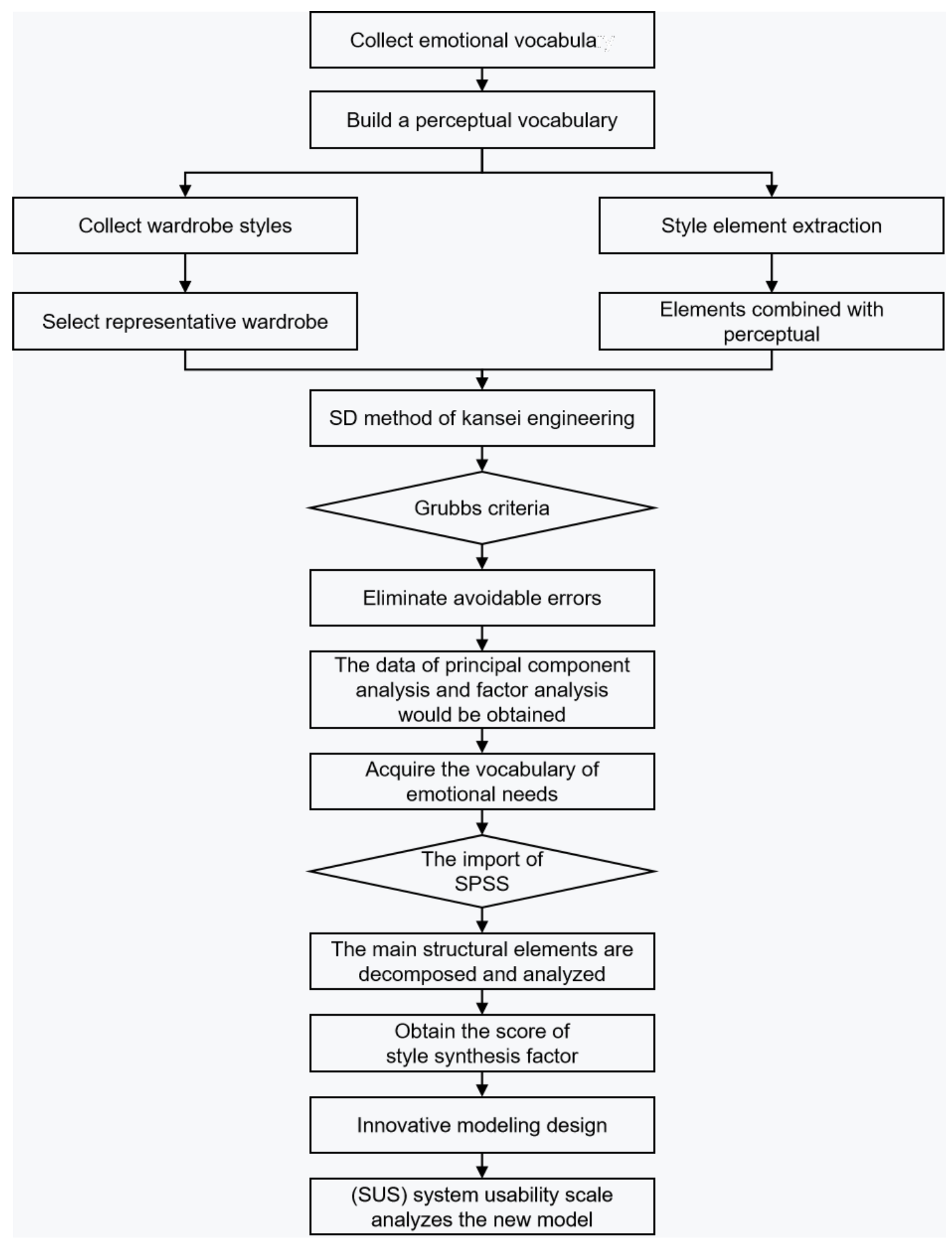

Figure 1. Design research flow

\section{Perceptual semantic space establishment and representative style selection}




\subsection{Establishing of perceptual lexical semantic space}

Through Internet search, newspapers, books, literature reading and interviews with experts, a large number of perceptual adjective words would be collected, such as high-end, low-end, simple and so on. These vocabularies would be mainly used to inform the subjects of their perceptual evaluation of a product, to express the subjects' perceptual needs through a number of adjectives, to improve the overall feelings of the subjects on the product. After that, the subjects could choose the most appropriate words for their own perceptual needs. A total of 214 perceptual words have been collected, screened and made into a questionnaire, which was provided to the users for the selection of perceptual words. A total of 300 copies of the questionnaire were distributed, and 247 valid questionnaires were returned to conduct further interpretation and analysis. As a result, 57 perceptual words with the highest frequency were selected. Finally, 3 research scholars and 10 design practitioners were consulted to screen out 8 perceptual words with the highest frequency, and the antonyms for these 8 perceptual words would be established to form 8 sets of perceptual image phrases, as shown in [Table 1].

Table 1. Vocabulary of perceptual images of the selected wardrobe

\begin{tabular}{|c|c|c|c|}
\hline \multicolumn{4}{|c|}{ Perceptual image vocabulary group } \\
\hline Simplicity - complexity & Fashion - conservative & $\begin{array}{c}\text { Easy to use - hard to } \\
\text { use }\end{array}$ & safety-danger \\
\hline Steady - childish & High-end to low-end & $\begin{array}{c}\text { Convenience - } \\
\text { inconvenience }\end{array}$ & Tough - soft \\
\hline
\end{tabular}

\subsection{Representative style search and screening}

Due to the differences of user's background, education level, aesthetic standard, in order to guarantee the accuracy of research conclusion and enable every user to have a better understanding of the characteristics of chest, 21 typical style were selected by searching the web resources and visit each big furniture store. And by taking advantage of the card classification and expert evaluation method, final six chest style types were retained. In order to avoid the influenced caused by color for designers and users in the experiment, the sample picture of every chest has been filtered by color processing. The final selected style is shown in [Figure 2], style 1 is the curved side wardrobe, style 2 is the u-shaped wardrobe, style 3 is the 1-shaped wardrobe, style 4 is the frame structure wardrobe, style 5 is the linear wardrobe, style 6 is the unstructured hanging wardrobe.

\section{Overall perceptual data analysis and modeling element data analysis}

\subsection{Representative style perceptual data analysis}

The above 6 wardrobe styles were combined with 8 perceptual words and the perceptual evaluation was carried out in the form of questionnaire. The users made corresponding perceptual score on the questionnaire through personal subjective judgment and established perceptual intention space. 


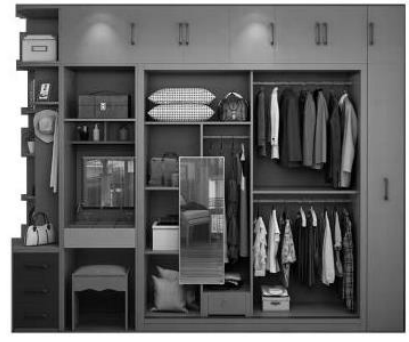

(a)Style 1

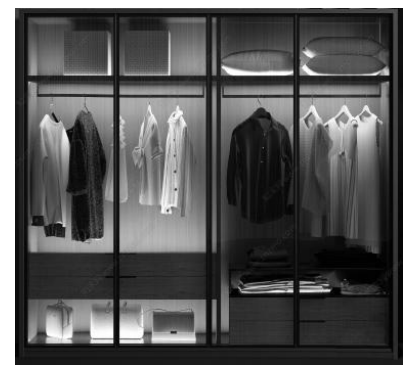

(d)Style 4

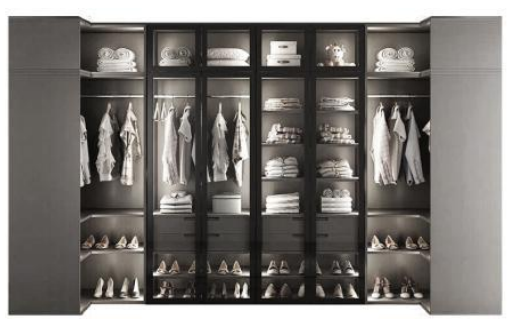

(b)Style 2

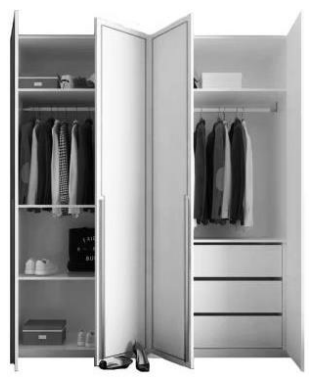

(e)Style 5

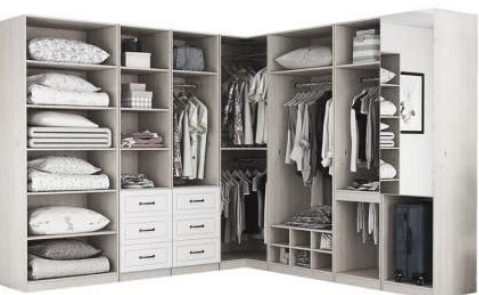

(c)Style 3

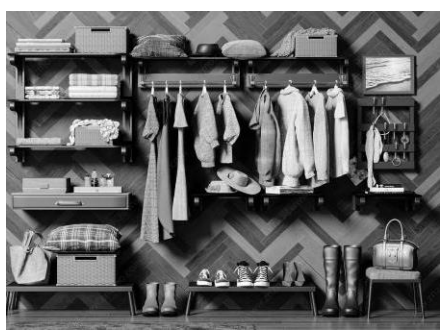

(f)Style 6

Figure 2. representative wardrobe style

The semantic difference, (SD method) was used in the questionnaires, which required the candidates to give score by following 7 Likert Scale Scores Method to each sample pictures respectively. And the choice of marks included -3, -2, -1, 0, 1, 2, 3. Among them, three points represented that the participant believed that the intentional vocabulary highly accorded with the style of the wardrobe, 0 points meant that the candidate had not any specific feeling towards the wardrobe style, adversely, giving -3 to the objects indicated that the intentional vocabulary did not match with the wardrobe style entirely in the candidate's perspective. A total of 300 questionnaires were issued and 210 valid questionnaires were returned. Based on the fact that the study mainly focuses on the middle and higher income groups, two choices of family annual income, (above RMB 360,000 yuan per year and below RMB 360,000 yuan per year) were set up in the questionnaire [16]. After the elimination of the invalid sample size, (whose yearly incoming is less than RMB 360,000 yuan), all valid questionnaires were numbered to obtain the following perceptual intention matrix:

$$
A=\left[\begin{array}{llll}
A_{11}^{k} & A_{12}^{k} & \cdots & A_{1 j}^{k} \\
A_{21}^{k} & A_{22}^{k} & \cdots & A_{2 j}^{k} \\
A_{31}^{k} & A_{32}^{k} & \cdots & A_{3 j}^{k} \\
\vdots & \vdots & \vdots & \vdots \\
A_{i 1}^{k} & A_{i 2}^{k} & \cdots & A_{i j}^{k}
\end{array}\right]
$$

In the formula: $A_{i j}^{k}----\mathrm{k}$ represents the evaluation score of the subjects of the KTH questionnaire on the JTH perceptual intention of the ith wardrobe style, $1 \leq k \leq 210$, $1 \leq i \leq 6,1 \leq j \leq 8$ 。

Considering that there may be some random deviations in the questionnaire data, it is necessary to select and judge the validity of data systematically. The Grubbs test method was used to examine the data and eliminate the abnormal values. Due to the fact that each valid 
questionnaires is independent, each value of the perceptual image subjects for each style is unique, the $\mathrm{k}$ subjects image is corresponding to the $\mathrm{k}$ value, the value of $\mathrm{j}$ a perceptual image also has the independence, the style of $\mathrm{j}$ a perceptual image value was presented as normally distribution, which has met the premise of Grubbs criteria.

According to the Grubbs criterion, if the conductor wants to examine whether there is an existence of abnormal values $A_{i j}^{k}$, it is necessary to list all 210 perceptual image measurement values in order, from small to large. Then, use $\mathrm{O}_{1}, \mathrm{O}_{2}, \ldots, \mathrm{O}_{210}$ to represent the measured value of the image after data ordering. According to Fu y b [17], it can be known that the maximum and minimum values in the numerical value need to be determined first whether they are abnormal values. The steps are as follows:

(1) select significance level $\beta$, then reliability $\mathrm{P}=1-\beta$.

(2) calculate the mean and standard deviation of each perceptual image phrase in perceptual image matrix A according to equations, (2) and, (3).

$$
\begin{gathered}
\overline{A_{l \jmath}}=\frac{A_{i j}^{1}+A_{i j}^{2}+A_{i j}^{3}+\cdots+A_{i j}^{k}}{k}=\frac{1}{k} \sum_{k=1}^{210} A_{i j}^{k} \\
\beta=\sqrt{\sum_{k=1}^{210}\left(A_{i j}^{k}-\overline{A_{\imath \jmath}}\right) 2 /(k-1)}
\end{gathered}
$$

Where, $k$ stands for the number of valid questionnaires.

(3) calculate the ratio $\mathrm{G}$ of residual and standard deviation. Assumed minimum $O_{1}$ if it is suspected to be an abnormal value, it can be calculated according to equation, (4). Then, assumed maximum $O_{210}$ as the suspected abnormal value, it can be calculated according to equation, (5).

$$
\begin{aligned}
G_{1} & =\frac{\left|\overline{A_{l \jmath}}-O_{1}\right|}{\beta} \\
G_{210} & =\frac{\left|O_{210}-\overline{A_{l \jmath}}\right|}{\beta}
\end{aligned}
$$

(4) The critical values of valid questionnaires $\mathrm{k}$ and a were queried according to Grubbs test threshold table $G_{P}(k)$ numerical value.

(5) To determine whether it is an outlier, if $\mathrm{G}>G_{P}(k)$, then the value is abnormal value, can be eliminated.

(6) The remaining 209 perceptual image measurements were calculated according to the above steps to determine whether they were abnormal values.

The filtered and judged values were rearranged and imported into SPSS 25.0 to calculate the mean values, as shown in [Table 2].

Table 2 mean value of perceptual evaluation of representative styles

\begin{tabular}{|c|c|c|c|c|c|c|c|c|}
\hline \multirow{2}{*}{$\begin{array}{c}\text { style } \\
\text { number }\end{array}$} & \multicolumn{9}{|c|}{\begin{tabular}{c} 
Perceptual imagery phrase \\
\cline { 2 - 10 }
\end{tabular}} & $\begin{array}{c}\text { Simplicity - } \\
\text { complexity }\end{array}$ & $\begin{array}{c}\text { Fashion - } \\
\text { conservative }\end{array}$ & $\begin{array}{c}\text { Easy to } \\
\text { use - hard } \\
\text { to use }\end{array}$ & $\begin{array}{c}\text { Safety } \\
\text {-danger }\end{array}$ & $\begin{array}{c}\text { Steady - } \\
\text { childish }\end{array}$ & $\begin{array}{c}\text { Senior } \\
- \text {-low }\end{array}$ & $\begin{array}{c}\text { Convenience - } \\
\text { inconvenience }\end{array}$ & $\begin{array}{c}\text { Tough } \\
- \text { soft }\end{array}$ \\
\hline 1 & -0.848 & -0.076 & -0.086 & -0.067 & -0.133 & 0.019 & -1.048 & -0.038 \\
\hline 2 & 0.371 & 0.038 & 0.029 & 0.010 & 0.000 & 1.057 & -0.400 & 0.324 \\
\hline 3 & -0.381 & -0.210 & 1.086 & 0.076 & -0.181 & 0.181 & -0.600 & 0.105 \\
\hline 4 & 0.114 & 0.314 & 2.010 & -0.048 & -0.181 & 0.067 & -0.543 & 0.400 \\
\hline 5 & 1.038 & -0.076 & 0.267 & -0.038 & -0.095 & -1.019 & -0.390 & 0.324 \\
\hline 6 & 1.133 & 0.038 & 0.305 & 0.219 & -0.743 & 0.305 & -1.010 & -0.086 \\
\hline
\end{tabular}




\subsection{Analysis of perceptual measurement of wardrobe style}

Due to the possible correlation between the data, the analysis may be complicated. Therefore, the mean value of perceptual imagery phrases would be analyzed by principal component analysis and factor analysis would benefit for understanding the correlation structure. The analysis of the association structure of perceptual image phrases is conducive to the analysis of the wardrobe modeling structure to avoid the important structure in the style is not extracted. The mean value of perceptual evaluation in [Table 2] was imported into the SPSS software for gravel diagram analysis, and the results showed that 8 groups of perceptual vocabulary were suitable for factor analysis, as shown in [Figure 3].

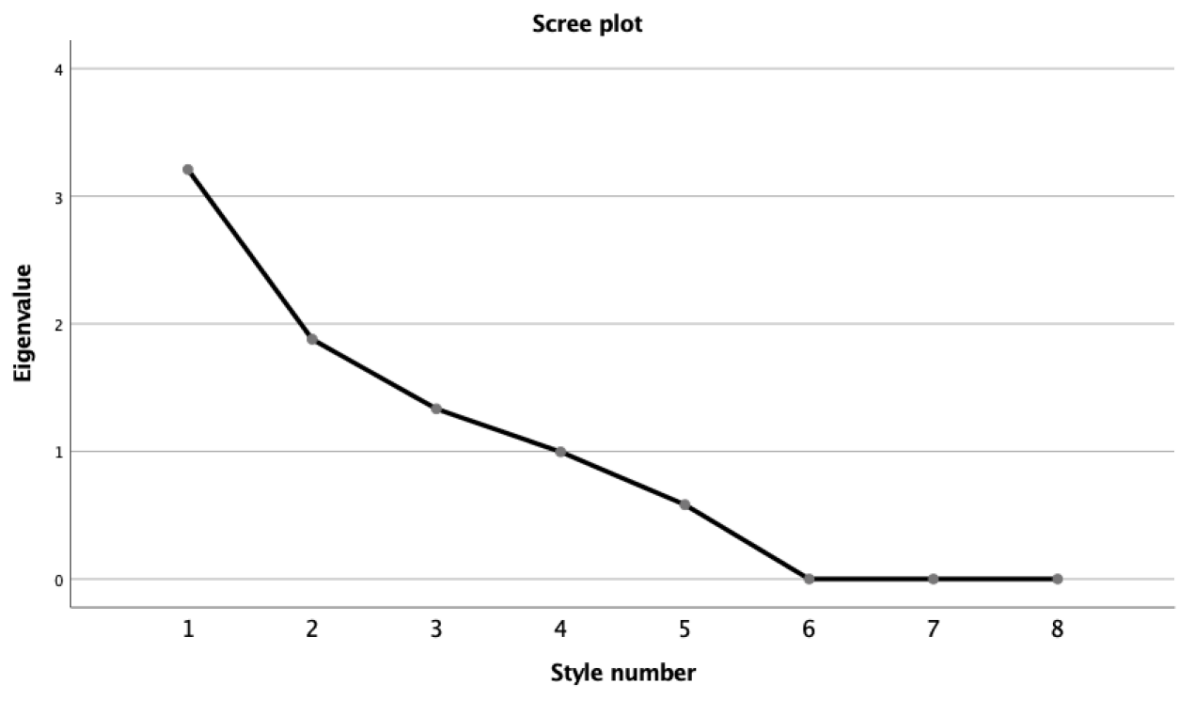

Figure 3. gravel diagram

The perceptual evaluation means in [Table 2] was imported into the SPSS software to obtain the characteristic root, variance contribution degree and cumulative variance contribution rate of the correlation among variables. As shown in [Table 3], the characteristic value of common factor $1 \mathrm{st}$, common factor 2 nd and common factor 3 rd is greater than 1 , which indicated that the influence index is bigger. Also, it figured iut the fact that the 3 principal components would have great impact on wardrobe modelling designing. The variance contribution of the first principal, second principal and the third principal component is $40.113 \%, 23.482 \%$ and $16.668 \%$ repsectively. After rotating load, it can be known that the variance contribution rate of the three principal components all changed, but the total cumulative variance contribution rate still kept constant. Meanwhile, it was still ranked from large to small, which was $35.348 \%, 24.593 \%$, and $20.323 \%$ from the 1st to the 3rd respectively. The total cumulative variance contribution rate was $80.263 \%$, higher than the standard index of $80 \%$, which indicated that the three principal components contained information in all indexes. Having a deep calculation of the importance of each perceptual vocabulary to the wardrobe design, three common factors for perceptual image vocabulary component matrix, as shown in [Table 4]. Setting principal component 1, principal component 2, and principal component 3 as $E_{1}, E_{2}$ and $E_{3}$, respectively, the coefficient matrix of three principal component pairs of each perceptual phrase would be shown in [Table 5]. 
Table 3. Extraction of principal components

\begin{tabular}{|c|c|c|c|c|c|c|}
\hline \multirow{2}{*}{$\begin{array}{c}\text { major } \\
\text { constituent }\end{array}$} & \multicolumn{3}{|c|}{ Initial Eigen value } & \multicolumn{3}{c|}{ Rotation Sums of Squared Loadings } \\
\cline { 2 - 7 } & total & $\begin{array}{c}\text { Variance } \\
\text { Proportion }\end{array}$ & Cumulative\% & total & $\begin{array}{c}\text { Variance } \\
\text { Proportion }\end{array}$ & Cumulative\% \\
\hline 1 & 3.209 & 40.113 & 40.113 & 2.828 & 35.348 & 35.348 \\
\hline 2 & 1.879 & 23.482 & 63.596 & 1.967 & 24.593 & 59.941 \\
\hline 3 & 1.333 & 16.668 & 80.263 & 1.626 & 20.323 & 80.263 \\
\hline
\end{tabular}

Table 4. Component matrix after rotation

\begin{tabular}{|c|c|c|c|}
\hline \multirow{2}{*}{ perceptual words } & \multicolumn{3}{|c|}{ Component load factor } \\
\cline { 2 - 4 } & principal component 1 & principal component 2 & principal component 3 \\
\hline contracted & -0.527 & 0.144 & 0.808 \\
\hline fashion & -0.058 & 0.890 & 0.003 \\
\hline Easy to use & 0.110 & 0.791 & -0.038 \\
\hline security & -0.917 & -0.053 & 0.017 \\
\hline composed & 0.980 & -0.032 & 0.052 \\
\hline senior & -0.157 & 0.291 & -0.548 \\
\hline convenient & 0.567 & 0.324 & 0.638 \\
\hline Hale and hearty & 0.622 & 0.578 & 0.511 \\
\hline
\end{tabular}

Table 5. Score coefficient matrix of components

\begin{tabular}{|c|c|c|c|}
\hline \multirow{2}{*}{ Image phrase } & \multicolumn{3}{|c|}{ Component score coefficient } \\
\cline { 2 - 4 } & $E_{1}$ & $E_{2}$ & $E_{3}$ \\
\hline Simplicity - complexity & -0.261 & 0.016 & 0.553 \\
\hline Fashion - conservative & -0.090 & 0.498 & -0.109 \\
\hline Easy to use - hard to use & -0.017 & 0.436 & -0.135 \\
\hline Safety-danger & -0.341 & 0.039 & 0.078 \\
\hline Steady - childish & 0.367 & -0.099 & -0.025 \\
\hline Senior-low & -0.045 & 0.244 & -0.391 \\
\hline $\begin{array}{c}\text { Convenience - } \\
\text { inconvenience }\end{array}$ & 0.146 & 0.054 & 0.344 \\
\hline Tough - soft & 0.156 & 0.208 & 0.224 \\
\hline
\end{tabular}

Factor scores of $E_{1}, E_{2}$ and $E_{3}$ in each style were calculated in SPSS software, represented by $b_{1}, b_{2}$, and $b_{3}$, and the composite factor scores of samples were calculated by combining the component coefficient scores in equation, (6) and [Table 5], represented by $\mathrm{B}$, as shown in [Table 6].

$B=(35.348 \% / 80.263 \%) \times b_{1}+(24.593 \% / 80.263 \%) \times b_{2}+(20.323 \% / 80.263 \%) \times b_{3}(6)$

where: $b_{1}$-- score of the common factor of the first style;

$b_{2}$-- score of common factor 2 of style;

$b_{3}$-- score of the third common factor of style. 
Table 6. scores of style synthesis factors

\begin{tabular}{|c|c|c|c|c|}
\hline style number & $b_{1}$ & $b_{2}$ & $b_{3}$ & $B$ \\
\hline 4 & 0.379 & 1.830 & -0.159 & 0.688 \\
\hline 5 & 0.485 & -0.670 & 1.760 & 0.454 \\
\hline 2 & 0.491 & 0.248 & 0.053 & 0.306 \\
\hline 3 & 0.180 & -0.375 & -0.398 & -0.137 \\
\hline 1 & 0.491 & -1.000 & -1.308 & -0.422 \\
\hline 6 & -2.026 & -0.033 & 0.052 & -0.889 \\
\hline
\end{tabular}

The [Table 4] shows that the emotional vocabulary Hale and Hearty more has a close relationship with component 1 . However, word Fashion and Fasy presents an apparently close relationship with composition. Similarily word the two perceptual vocabulary Simple and Convenient is more close to component 3 . And those values which are more than 0.6 would be regarded as default extract standard [18], which indicates that it could meet the demand of higher income people in perceptual. [Table 6] shows that the wardrobe modelling of 4, 5, 2 could be more accepted by consumer, especially for the open linear modelling in style 4, which can get the apperception of consumer more easily. However, the comprehensive factor score of style 3, 1 and 6 is low, indicating that their modeling features are not the style expected by middle and high income groups. Based on this, the steady, tough, stylish, easy to use, simple and convenient in table 4 have different performances in style 4, 5 and 2. Taking the wardrobe current situation, visual effect and functional structure these perspectives into analysis, it is easy to know that the wardrobe in the style of concise and easy appearance with the integral modelling of linear structure, square dress mirror, convenient to see seek and easy to operate wardrobe structure, contracted, hard and safe hang clothes pole would be more preferred by high income crowds..

\subsection{Wardrobe modeling elements decomposition}

In product design, various factors should be considered, such as shape, color matching, function, meaning, technology and so on. Wardrobe in perceptual image is more related to the higher income people's visual feeling, function and operation experiences, especially in the visual effect and personal understanding of the whole wardrobe structure to evaluate chest satisfaction, including the structure of the wardrobe partitions. These information such as material, the information is closely related with the design of a whole wardrobe. Accordingly, wardrobe modelling design element is decomposed with product structure, function. Through the comprehensive evaluation of the representative style of the existing wardrobe, it is concluded that the six main components that mainly affect the wardrobe model are: hanging clothes pole, wardrobe door, dressing mirror, drawer, side area, integral line.

\subsection{Correlation between perceptual image vocabulary and modeling elements}

After the analysis of the article, in order to ensure the rationality and accuracy of the wardrobe overall modeling, the main parts and the corresponding perceptual image vocabulary would be combined to establish a correlation model. This part USES the modelling chart would be used to carry on the modelling decomposition to the wardrobe main part, analyzing the modelling image which is similar to it, providing the reference direction for the follow-up product concept visualization. By combining perceptual vocabulary with main parts, questionnaire survey was conducted to obtain perceptual image vocabulary and 
design elements with high repetition rates, which were analyzed and integrated, as shown in [Table 7].

Table 7. correlation between perceptual image and design elements

\begin{tabular}{|c|c|c|c|c|c|c|c|c|c|}
\hline part & $\begin{array}{l}\text { Modelling } \\
\text { elements }\end{array}$ & $\begin{array}{c}\text { contract } \\
\text { ed }\end{array}$ & fashion & $\begin{array}{c}\text { Easy to } \\
\text { use }\end{array}$ & security & $\begin{array}{c}\text { compos } \\
\text { ed }\end{array}$ & senior & $\begin{array}{c}\text { conveni } \\
\text { ent }\end{array}$ & $\begin{array}{c}\text { Hale } \\
\text { and } \\
\text { hearty }\end{array}$ \\
\hline \multirow{5}{*}{$\begin{array}{l}\text { clothes ra } \\
\text { il }\end{array}$} & Rotundity & $\Delta$ & & & & $\Delta$ & & $\Delta$ & $\triangle$ \\
\hline & Oval & & & $\nabla$ & & & & & $\Delta$ \\
\hline & $\mathrm{H}$ rectangle & & & & $\triangle$ & & & & $\triangle$ \\
\hline & Gear shape & & $\nabla$ & $\triangle$ & & & $\nabla$ & $\nabla$ & \\
\hline & Free type & & $\triangle$ & & $\nabla$ & & & & $\nabla$ \\
\hline \multirow{3}{*}{$\begin{array}{c}\text { cabinet } \\
\text { door }\end{array}$} & rectangle & $\Delta$ & & $\Delta$ & & $\Delta$ & & $\triangle$ & $\triangle$ \\
\hline & $\begin{array}{c}\text { The shutter } \\
\text { type }\end{array}$ & & $\triangle$ & & & & & & \\
\hline & $\begin{array}{l}\text { collapsible } \\
\text { type }\end{array}$ & & & & $\nabla$ & & & & \\
\hline \multirow{3}{*}{$\begin{array}{l}\text { wardrobe } \\
\text { mirror }\end{array}$} & rectangle & $\triangle$ & & & $\nabla$ & $\Delta$ & & & \\
\hline & Oval & & & & $\nabla$ & & & & $\nabla$ \\
\hline & $\begin{array}{l}\text { rounded } \\
\text { rectangle }\end{array}$ & $\triangle$ & $\triangle$ & & & & & & \\
\hline \multirow{2}{*}{$\begin{array}{c}\text { drawer } \\
\text { door }\end{array}$} & Draw type & & & $\triangle$ & & & & & \\
\hline & $\begin{array}{l}\text { Side pull } \\
\text { type }\end{array}$ & & & & & & & $\triangle$ & \\
\hline \multirow{2}{*}{ side part } & $\begin{array}{l}\text { A square } \\
\text { line }\end{array}$ & & & $\nabla$ & & & & & \\
\hline & $\begin{array}{l}\text { Curved } \\
\text { lines }\end{array}$ & & $\triangle$ & & & & $\boldsymbol{\Delta}$ & $\triangle$ & \\
\hline $\begin{array}{c}\text { Chest } \\
\text { type body }\end{array}$ & L type & & & & $\triangle$ & & & & \\
\hline
\end{tabular}




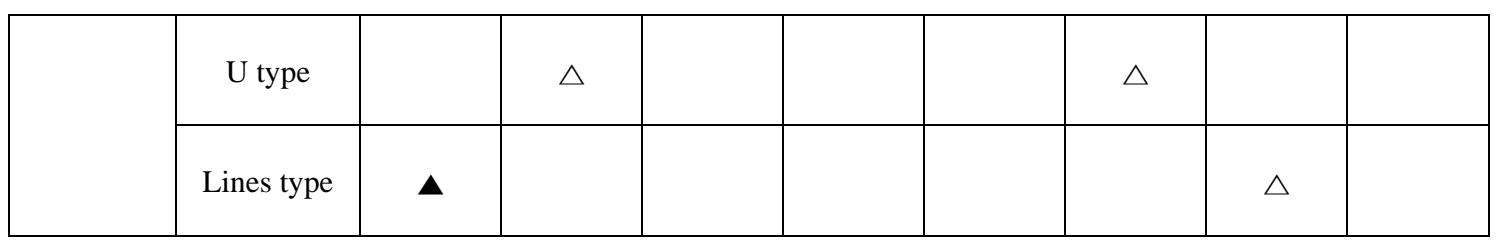

Note: score of design elements $>0.5$ marked as $\boldsymbol{\Lambda}$; score $<-0.5$ marked as $\boldsymbol{\nabla}$;score $>0.3$ and $<0.5$ marked as $\triangle$;score $<-0.3$

and $>-0.5$ marked as $\nabla$.

[Table 7] takes the image vocabulary as the criterion variable, and the modeling design elements of each part as the prediction variable. According to the correlation between two types of variables, the importance of each modeling design element in the image vocabulary would be reflected. Therefore, it could be seen that the clothes rail, the wardrobe door and the dressing mirror have greater influence on the perceptual image of the wardrobe. Circular clothes rail and rectangular wardrobe doors have apparent advantages in showing the simple and calm style. Circular clothes rail performs best at the aspect of convenience, the perceptual image in fashion and convenience acts as constraints on the overall wardrobe modeling design. According the key characteristics of the main parts mentioned above, the design basis should consider the circular clothes rail, rectangular wardrobe door, rectangular dressing mirror, straight pulling drawer, the side part with curved lines and linear integrated wardrobe. Combined with [Table 7], innovative modeling design is carried out for these six key parts.

\section{Wardrobe design}

\subsection{Design ideas}

Based on the above analysis of the whole and part of the wardrobe, with style 4 as the main reference object, combined with style 5 and style 2, with the overall wardrobe design linear Add distinct structure of clothing placement; Rectangular floor-to-ceiling mirror; Cylindrical clothes hanging rod; Make integral wardrobe shows composed and safe appearance characteristic. The resulting conceptual design sketch is shown in [Figure 4].
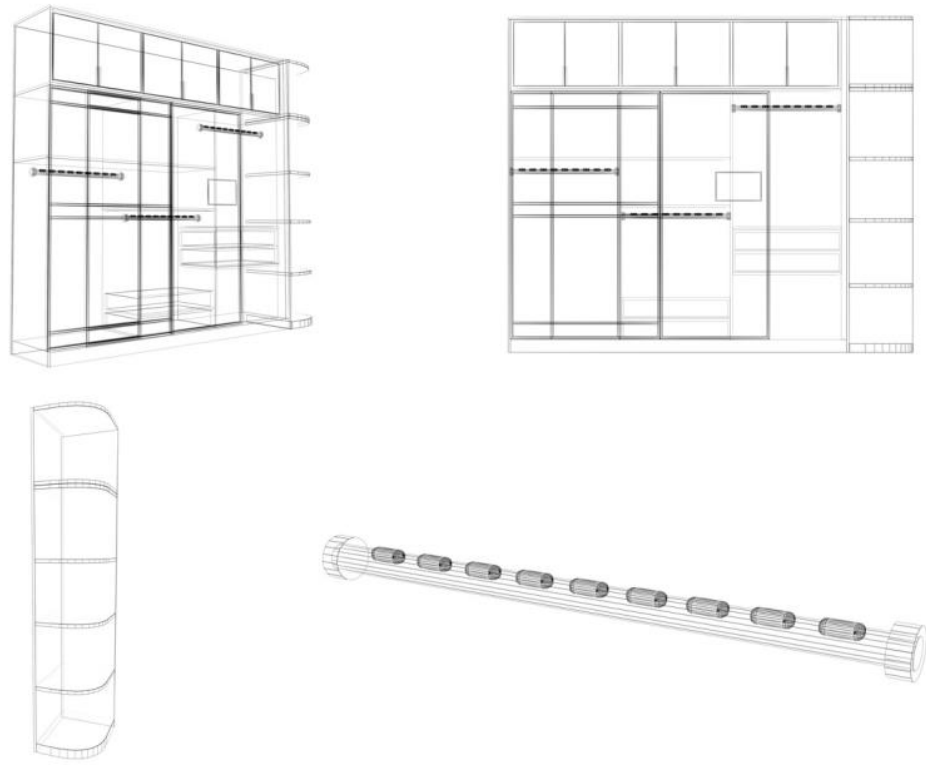

Figure 4. Wardrobe design sketch 


\subsection{Product modeling design}

Through the form of design sketch, and communicating with 3 wardrobe experts and 7 design practitioners, the strong and steady overall wardrobe features would be confirmed eventually, which could reflect a simple but general visual characteristics. Adding floodlight in each structural area, the wardrobe could provide the consumer a kind of ease and sense of security under the influence of lamplight. The clothes rail adopts a circular structure and a lampring is added to enhance the visual experience of taking and hanging clothes. Wardrobe can be placed commonly indoor, which is relatively inside area. And the design of dress mirror combines the partial electronic screen with tawny glass photograph to, make dress mirror intelligent, It enable the consumers to know the weather condition outside and current affairs news at the same time while trying on a dress. The final $3 \mathrm{~d}$ rendering of the product is shown in [Figure 5].
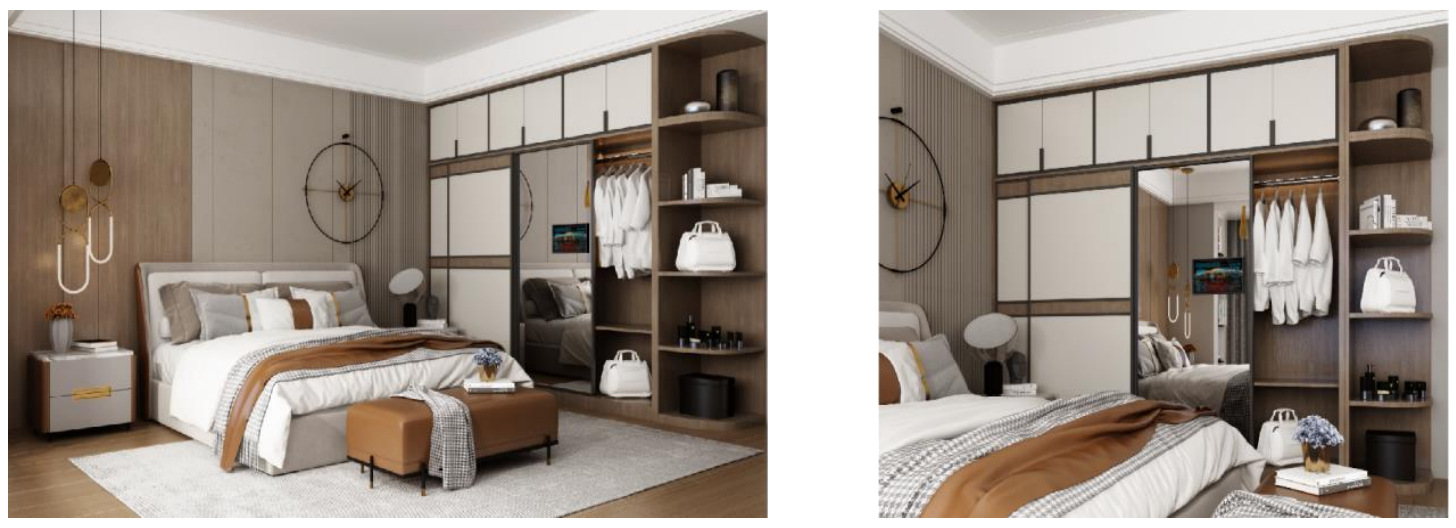

Figure 5. 3d modeling design scheme effect diagram

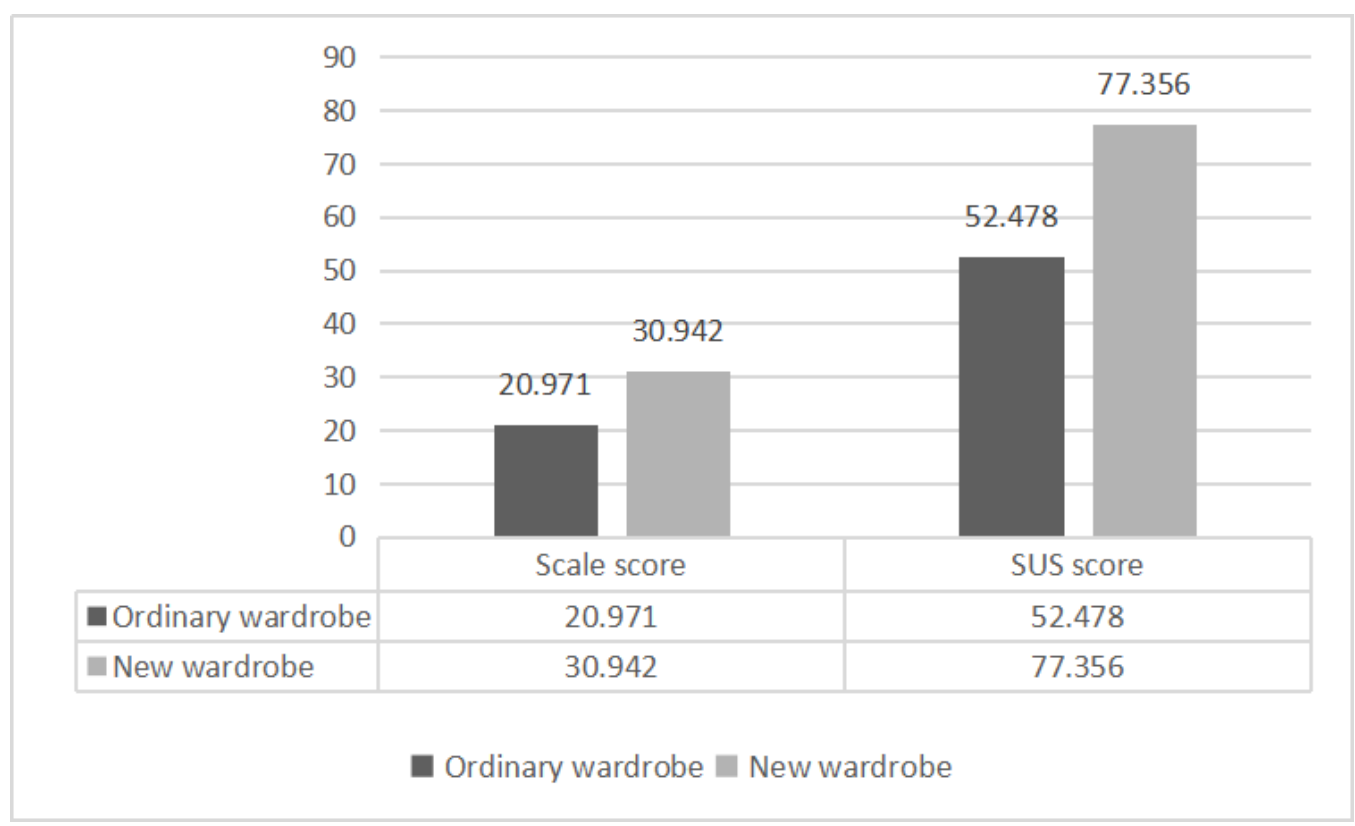

Figure. 6 SUS system availability scale 
In order to verify the satisfaction of the design scheme, the systematic usability scale, (SUS) was used to conduct a questionnaire survey on the modeling image of newly designed wardrobe design scheme and ordinary wardrobe [19]. A total of 120 questionnaires were issued and 104 valid questionnaires were returned and collected. The first step in calculating the SUS score is to determine the conversion score for each question, which ranges from 0 to 4. For heads, (odd), the conversion score is the original score minus $1,(\mathrm{Xi}-1)$, and for tails, (even), the conversion score is 5 minus the original score, (5- Xi). The total score of SUS was obtained by adding up the conversion scores of all items and multiplying by 2.5 . So SUS scores range from 0 to 100 , incremented by 2.5 . The redesigned wardrobe scored higher on the SUS scale, above 80 points. As shown in [Table 8], it shows that the wardrobe design scheme is suitable for the emotional needs of middle and high income people.

Table 8. curve grading range of SUS score

\begin{tabular}{|c|c|c|c|c|c|}
\hline $\begin{array}{c}\text { SUS score } \\
\text { rating }\end{array}$ & rating & $\begin{array}{c}\text { Percentile } \\
\text { rank }\end{array}$ & $\begin{array}{c}\text { SUS score } \\
\text { rating }\end{array}$ & rating & $\begin{array}{c}\text { Percentile } \\
\text { rank }\end{array}$ \\
\hline $84.1-100$ & A+ & $96-100$ & $71.1-72.5$ & C+ & $60-64$ \\
\hline $80.4-84$ & A & $90-95$ & $65-71$ & $\mathrm{C}$ & $41-59$ \\
\hline $78.9-80.7$ & A- & $85-89$ & $62.7-64.9$ & C- & $35-40$ \\
\hline $77.2-78.8$ & B+ & $80-84$ & $51.7-62.6$ & $\mathrm{D}$ & $15-34$ \\
\hline $74.1-77.1$ & B & $70-79$ & $0-51.7$ & $\mathrm{~F}$ & $0-14$ \\
\hline $72.6-74$ & B- & $65-69$ & & & \\
\hline
\end{tabular}

\section{5. conclusion}

Based on the kanse engineering theory, this study used the semantic difference method to screen the perceptual images and their measured values of representative wardrobes, and used Grubbs criterion to judge and eliminate outliers, so as to accurately obtain the quantitative degree of each representative wardrobe style to image vocabulary. Based on the data analysis, the main factor which affects the wardrobe design elements could be figured out. Also, the importance of the style of the wardrobe could be figured out. After that, analyzing the six major characteristics of the parts and elements of decomposition in wardrobe, the style that meets the demand of higher income people in the image of chest design could be obtained. And after being verified by SUS scale in their feasibility of the design scheme, it could provide theoretical support for the future chest model design.

\section{References}

[1] Qianzhan industry research institute, "2020-2025 China furniture industry market demand forecast and investment strategy planning analysis report," China: qianzhan industry research institute, (2020)

[2] Luo Shijian and pan yunhe, "Research progress of perceptual image theory, technology and application in product design," Journal of mechanical engineering, vol.43, no.3, pp.8-13, (2007)

[3] Zhou xiaoxi and liang huie, "Effect evaluation of clothing fabric design based on perceptual image," Journal of textiles, no.4, pp.60-64, Long the town grow, (2015)

[4] "The perceptual technology: perceptual Live in the design technology," Tokyo: HaiWenTang. Press, (1989) 
[5] Nagamachi m. "sei engineering: a new ergonomic consumer-oriented technology for product development," International Journal of Industrial Ergonomics, vol.15, no.1, pp.3-11, (1995)

[6] Li faquan, xiong deide, and Tang Xinkui, et al. "Development and analysis of research on design cognitive process," Computer engineering and applications, vol.47, no.20, pp.24-27, (2011)

[7] Luo Shijian and zhu shangshang, "Perceived image of product modeling by users and designers," Journal of mechanical engineering, vol.41, no.10, pp.28-34, (2005)

[8] Bouchard C, Mantelet F, and Aoussat A, et al. "A European emotional investigation in the field of shoe design,” International Journal of Product Development, vol.7, no.1/2, pp.3, (2009)

[9] Zhafira N, Putra P S, and Rahmillah F I, et al. "Innovative design of ironing board based on Kansei Engineering and usability test," Matec Web of Conferences, vol.154, (2018)

[10] Chen C C and Chuang m. c. "Integrating the Kano model into a robust design approach to enhance customer satisfaction with the product design," International Journal of Production Economics, vol.114, no.2, pp.667681, (2008)

[11] Tama I P, Azlia W, and Hardiningtyas d. "Development of customer oriented product design using kansei engineering and kano model:case study of ceramic," Procedia Manufacturing, vol.4, pp.328-335, (2015)

[12] Su jianning, zhao huijuan, and wang ruihong, et al. "Product image modeling optimization design based on support vector machine and particle swarm optimization algorithm," Mechanical design, vol.32, no.1, pp.105109, (2015)

[13] Xiao wangqun, cheng jianxin, and zhou xue, et al. "Research on perceptual image space of modeling design elements of industrial robots based on eye movement experiment," Mechanical design, vol.34, no.7, pp.124128, (2017)

[14] Shuo - Fang Liu, Yuan-chin Hsu, and hung-cheng Tsai, "Development of a new cultural design process using Kansei engineering and fuzzy techniques a case study in Mazu crown design," International Journal of Clothing Science and Technology, vol.5, no.31, pp.663-684, (2020)

[15] Wang nian-wen, wang jian, "Research on modeling design of family service robots for emotional needs," Mechanical design, vol.35, no.11, pp.111-116, (2008)

[16] "National bureau of statistics of China. Statistical bulletin of national economic and social development in 2019," Beijing: national bureau of statistics, (2019)

[17] Fu y b, Yang l, and yu f b., "application of Microsoft Excel in environmental monitoring data processing -Grubbs inspection outlier data," Sichuan environment, no.6, pp.107-109., (in Chinese, (2004)

[18] Yu kaimin, zhou xinli, and xiao fei, "Risk factor analysis of aircraft aircraft material support based on SPSS factor analysis," Journal of naval aeronautical engineering college, vol.30, no.4, pp.368-371, (2015)

[19] Bangor, A., Kortum, p. t., and Miller, j. t., "Determining what individual SUS scores mean: Adding an adjective rating scale,” Journal of Usability Studies, vol.4, no.3, pp.114-123, (2009) 